International Journal of Trend in Scientific Research and Development (IJTSRD)

Volume: 3 | Issue: 3 | Mar-Apr 2019 Available Online: www.ijtsrd.com e-ISSN: 2456 - 6470

\title{
Design for Additively Manufactured Structure: An Assessment
}

\author{
Deependra Sharma1, Prof. Vivek Babele ${ }^{2}$ \\ ${ }^{1}$ Research Scholar, ${ }^{2} \mathrm{Head}$ of Department \\ 1,2Department of Mechanical Engineering, RGPM, Bhopal, India
}

How to cite this paper: Deependra Sharma / Prof. Vivek Babele "Design for Additively Manufactured Structure: An Assessment" Published in International Journal of Trend in Scientific Research and Development (ijtsrd), ISSN: 24566470, Volume-3 I Issue-3, April 2019, PP. 85-87. URL: http://www.ijtsrd.co $\mathrm{m} /$ papers/ijtsrd2167 4.pdf

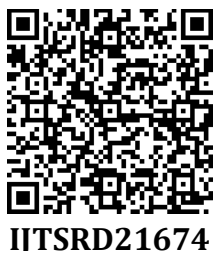

Copyright (C) 2019 by author(s) and International Journal of Trend in Scientific Research and Development Journal. This is an Open Access article distributed under the terms of the Creative Commons

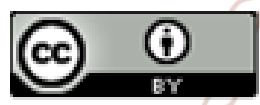
Attribution License (CC BY 4.0) (http://creativecommons.org/licenses/ by/4.0)

\section{INTRODUCTION}

One of the objectives of structural design is to minimize the mass consumption and maximize the utilization efficiency of the materials. Therefore, lightweight structure design has always been sought after for almost all the engineering designs. Lightweighting brings about various technical advantages such as high strength to weight ratio, high energy absorption per weight ratio, low thermal conductivity, and large surface area to volume/weight ratio. These attributes could in turn translate into various economical and environmental benefits such as product reliability, system energy efficiency and product sustainability. However, as lightweight designs often involve high level of geometrical complexity, the realization of these designs has been a challenging task with traditional manufacturing technologies. It has been widely recognized that additive manufacturing

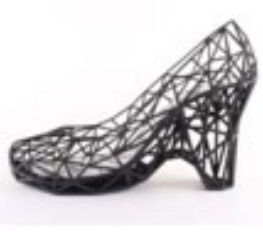

a. Fashion shoes

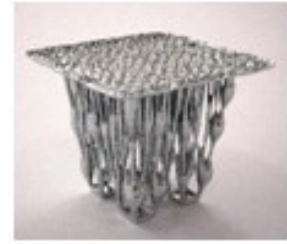

b. Table

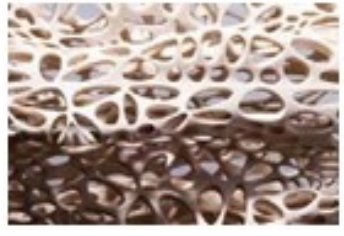

c. Skin shell

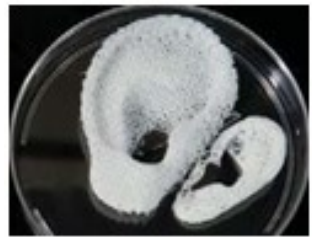

d. Artificial ear

Fig.1 Lightweight designs realized via AM in art, fashion and biomedicine 
While there exist various geometry design and optimization approaches and tools that generally allows for the creation of models with improved lightweight performance, currently none of them addresses the process designs adequately. Most of the lightweight design tools treat material as an ideal isotropic material and focus on geometry optimization only, which often results in a significant design deviation from reality. One of the unique characteristics of AM is that the material properties are often process and geometry dependent. Such coupling effect has significant impact in the design practice of lightweight structures, since these structures often have geometrical features that have varying dimensions and therefore potentially varying material properties. In addition, due to the intrinsic quality variations with many AM processes with small-dimension geometries, the difficulty of achieving accurate design is further signified. In this paper some of the works in the attempt to tackle this design dilemma is presented. A design methodology that includes geometrical design and material property design was proposed, and some of the issues during the establishment of this methodology was discussed.

\section{LITERATURE SURVEY}

Yu and Li et al.[1991] This paper proposes to use solid offset to cut down the solid volume to be built. The background theory for obtaining the reduced-volume solid is negatively offsetting the CSG The approach is applicable to solids defined by constructive solid geometry (CSG)

Ganesan and Fadel et al [1993] A simple effective method is presented here for creating (outside of the solid modeler) hollow CAD models of the object using offsetting techniques. This method is not suitable for creating hollow parts that have varying surface normals.

Koc and Lee et al.[1993] This paper presents a new method of using non-uniform offsetting and biarcs fitting to hollow out solid objects or thick walls to speed up the part building processes on rapid prototyping (RP) systems. Offset STL model contains some triangular facets with overlaps and inconsistent orientations.

Qu and stucker et al [1994] This paper presents a new 3D offset method for modifying CAD model data in the STL format. In this method, vertices, instead of facets, are offset. The magnitude and direction of each vertex offset is calculated using the weighted sum of the normals of the facets that are connected to each vertex.

Liu and Chen et al.[1996] presented to meet the demands of hollowed prototypes in casting and rapid prototype manufacturing. Offsetting along the $\mathrm{Z}$-axis and cross sectional contour offsetting are employed to perform the hollowing operation.[

Dutra et al et al.[1998] measured the stiffness of Ti-6Al-4V open cellular foams fabricated by electron beam melting (EBM). Results are found to be in good agreement with the Gibson-Ashby model for open cellular foam materials Wang and McDowell have performed a comprehensive review of analytical modeling, mechanics, and characteristics of various metal truss baseds.
Garcia et al [1999] CNTs were grown on alumina fiber cloth. These fibers were used as reinforcements in matrix material. The growth of CNTs led to an increase in inter-laminar shear properties of the order of $69 \%$ as compared to alumina cloth composite the elastic properties of FFRC (Fuzzy fiber reinforced composite) using mechanics of materials approach and Mori-Tanaka method considering with and without the interphase between CNT and polymer.

Johnson et al. [2000] provided a more comprehensive analytical model of the truss structure by considering each strut as a beam experiencing axial, bending, shearing, and torsion effects. He analyzed the octet-truss structure inside finite-element environment using a unit-truss model that consists of a node and set of half-struts connecting to the node.

Chang et. al. [2005] A standard thermosetting liquid resin, with the commercial brand name Quires 406 PA is used in the matrix in the form of orthophthalic unsaturated polyester (UP). It is acquired from the company MR-Dinis dos Santos (Lisbon, Portugal) and its characteristics are presented.

\section{PROBLEM IDENTIFICATION}

Design of cellular solid is often a difficult task using existing CAD packages due to the level of complexity associated with it. Designed by FDM is tested for RTM application.

The complete process should be integrated with the existing CAD platform

\section{RESEARCH OBJECTIVE}

Generate and design periodic cellular structures e.g Truss shaped

- Whole program is automated using VB script programming and is validated for many complex shaped parts.

Compression strength of the truss structure is observed to increase with the increase in the volume fraction and this behaviour is compared with an existing Wierzbicki expression, developed for predicting compression properties.

\section{CONCLUSIONS}

In this paper, the challenges of AM lightweight structurewere briefly reviewed.Compared to other design methodology such as topology optimization, unit cell based cellular design method appears to provide a good compromise between functionality and manufacturability. However, in order to pursue this design approach, various additional factors must be considered, such as size effects and material property dependency on both geometrical designs of the struts and the process planning. It was found that the homogenization treatment could not be readily applied to cellular structures in general, which poses a rather challenging obstacle in adopting this design method in the design of actual structures. Due to the complexity of cellular structures, it is currently inefficient to perform the designs using finite element simulation based methods. However, if the cellular structures could not be treated as continuous solid materials with equivalent properties, the limitation of analytical modeling must be overcome through overmeans. 


\section{REFERENCES}

[1] I. Zein, D. W. Hutmacher, K. C. Tan, S. H. Teoh. Fused deposition modeling of novel scaffold architectures for tissue engineering applications. Biomaterials. 23(2002), 4: 1169-1185.

[2] D. W. Rosen. Design for additive manufacturing: a method to explore unexplored egions of the design space. Proceedings of the Solid Freeform Fabrication (SFF) Symposium, Austin, TX, 2007.

[3] M. Castilho, M. Dias, U. Gbureck, J. Groll, P. Fernandes, I. Pires, B. Gouveia, J. Rodrigues, E. Vorndran. Fabrication of computationally designed scaffolds by low temperature 3D printing. Biofabrication. 5(2013), 3: 035012, R. Kuhn, R. F. B. Minuzzi. The 3d printing's panorama in fashion design. Proceedings of 5th Documenta Fashion Seminar and 2nd International Congress of Memory, Design and Fashion, Sao Paulo, Brazil, 2015.

[4] B. Z. Wang, Y. Chen. The effect of 3D printing technology on the future fashion design and manufacturing. Applied Mechanics and Materials. 496-500(2014): 2687- 2691. Accessed July 2016.

[5] http://www.3ders.org/articles/20120821-continuumfashion-launches-custom-3d-printed-shoes.html. Accessed July 2016.

[6] Francis Bitonti Studio. http://www.francisbitonti.com/fiber-tables/. Accessed July 2016.

[7] Neri Oxman: Projects. http://www.materialecology.com/projects. Accessed July 2016.
[8] Wake Forest Institute of Regenerative Medicine. http://www.wakehealth.edu/ WFIRM/. Accessed July 2016.

[9] M. P. Bendsoe, O. Sigmund. Topology Optimizaiton: Theory, Methods and Applications. Springer-Verlag, Berlin, Germany, 2003.

[10] Ing. T. Bechtold. Structural topology optimization for MEMS design. University of Freiburg, 2013.

[11] G. Chahine, P. Smith, R. Kovacevic. Application of topology optimization in modern additive manufacturing. Proceedings of Solid Freeform Fabrication (SFF) Symposium, Austin, TX, 2010.

[12] U. Maheshwaraa, C. C. Seepersad, D. Bourell. Topology design and freeform fabrication of deployable structures with lattice skins. Proceedings of Solid Freeform Fabrication (SFF) Symposium, Austin, TX, 2007.

[13] N. P. Fey, B. J. South, C. C. Seepersad, R. R. Neptune. Topology optimization and freeform fabrication framework for developing prosthetic feet. Proceedings of Solid Freeform Fabrication (SFF) Symposium, Austin, TX, 2009.

[14] A. Aremu, I. Ashcroft, R. Hague, R. Wildman, C. Tuck. Suitability of SIMP and BESO topology optimization algorithms for additive manufacture. Proceedings of Solid Freeform Fabrication (SFF) Symposium, Austin, TX, 2010

[15] E. Biyikli, A. C. To. Proportional topology optimization: a new non-gradient method for solving stress constrained and minimum compliance problems and its implementation in MATLAB. Computational Engineering, Finance, and Science. 12(2015): e0145041. 